\title{
The Response of Pakistan to COVID-19 and Current Situation of Disease in the Country
}

\author{
Rizwan Ullah, Ibrar Khan'1, Aneela Rehman 1,*, Azam Hayyat', Mujaddad ur Rehman', Salvatore Massa ${ }^{2}$ \\ 1Depatment of Microbiology, Abbottabad University of Science and Technology, Pakistan. \\ ${ }^{2}$ Faculty of Medicine, University of Foggia, Italy.
}

\section{ABSTRACT}

Background: Coronavirus 2019 (COVID-19) was reported for the first time in China and then quickly spread to other countries. In Pakistan, the first case appeared in Sindh province on February 26, 2020, and within a few weeks, more than 100 cases were reported across the country. Currently, all provinces and territories of the country are affected and cases are growing faster every day. Pakistan is among those countries that have problems with health and diagnostic facilities due to poor economic conditions.

Objectives: The present review aims to highlight the emergence, spread and control of the disease in Pakistan. Furthermore, it also highlights the response of Pakistan in the management of COVID-19 outbreak, and the country's contribution in the field of science and technology for the betterment of diagnostic and treatment capabilities against the disease.

Methodology: Collection of data was done through national and international forums like Covid-WHO report and COVID-19 Health advisory platform by Ministry of National Health Services Regulation.

Results: The important mean for prevention is the proper use of Standard Operating Procedure (SOPs). Quarantine and isolation centers help in limiting the spread of this deadly disease.

Conclusion: It is concluded that no vaccine is available for the treatment of this emerging disease so far. The only prevention is to properly and strictly follow the SOPs guidelines.

$\begin{array}{lcl}\text { Keywords } & \text { *Address of Correspondence } & \text { Article info. } \\ \text { Coronavirus, COVID-19, Pakistan, Outbreak, } & \text { aneelarehman88@gmail.com } & \text { Received: August 21, 2020 } \\ \text { Death cases } & & \text { Accepted: December 19, 2020 }\end{array}$

Cite this article: Ullah $R$, Khan I, rehman A, Hayyat A, rehman MU, Massa S. The Response of

Pakistan to COVID-19 and Current Situation of Disease in the Country. RADS J Biol Res Appl Sci. 2020; 11(2):159-163.

This is an Open Access article distributed under the terms of the Creative Commons Attribution License (http://creativecommons.org/licenses/by/4.0), which permits unrestricted use, distribution, and reproduction in any medium, provided the original work is properly cited.

\section{INTRODUCTION}

Viral-disease-outbreak's emergence has caused many serious public health issues in the past, and is still expected to occur in future. Epidemics of severe acute respiratory syndrome coronavirus (SARS-CoV) in 20022003 and Middle East respiratory syndrome coronavirus (MERS-CoV) in 2012 have been recorded previously. It was December 2019 when another viral outbreak occurred in Wuhan city, Hubei province, China and has affected more than 210 countries across the World.
The World Health Organization (WHO) declared the COVID 19 outbreak as sixth public health of emergency Services (SPHEC) on January 3, 20201. Initially, the infected individuals exposed respiratory disease symptoms with unknown aetiology, hence called pneumonia of unknown aetiology, and later on novel coronavirus pneumonia (NCP)2. World Health Organization (WHO) and Chinese Centre for Disease Control and Prevention (China CDC) started an investigation of the disease and they found the severe 
acute respiratory coronavirus-2 (SARS-CoV-2) as the causative agent of coronavirus disease-2019 (COVID-19). Initially, the disease remained limited to Wuhan city and China, but due to contagious nature of the virus, cases were also reported in other countries, hence WHO declared it a Pandemic on March 11, $2020^{3}$.

The current outbreak has so far resulted in more than 32730945 confirmed cases and 991224 deaths worldwide and it is continuously increasing. The highest number of cases and deaths were seen in United States of America (USA) and as of September 27, 2020, there were more than 16233110 cases and 546864 deaths ${ }^{4}$. In Pakistan, the two confirmed cases of COVID-19 appeared in Sindh, province of Pakistan and Islamabad capital on February 26, 2020. Following the two cases' history, it was found that they had travelled from Taftan, Iran border. Later on, within 15 days the coronavirus disease- 19 positive cases in Pakistan reached more than 40, highest in Sindh province. About $75 \%$ cases had the history of travelling from Iran, and remaining were from UAE and other countries ${ }^{5}$.

In the current situation, number of cases and deaths have been increasing day by day in Pakistan. According to the Ministry of National Health Services of Pakistan, confirmed cases of COVID-19 in Pakistan as of September 29, 2020, were 311,516 and deaths were 6,474 . The highest number of cases $(136,395)$ and deaths $(2,495)$ were seen in Sindh province 6 .

Importantly, the reported incubation period of virus is from 2 to 14 days and common symptoms of the disease include fever, cough, sneezing, breathlessness and headache. Some people remained asymptomatic but they have been a source of disease transmission to others ${ }^{7}$. Diagnostic procedures include isolation of suspected persons and collection of the sample through sterile swab from throat or nose. Sometimes, blood samples are also taken for pathological determination. Samples are properly processed for identification of virus through Reverse Transcription- Polymerase Chain Reaction (rRT-PCR) or Nucleic Acid Amplification Test (NAAT), serological tests, detection of IgM and IgG antibodies and Lungs CT scan. According to the Ministry of Science and Technology, Pakistan, scientists of National University of Science and Technology (NUST) have developed more reliable and accurate diagnostic kits that were approved from Drug Regulatory Authority of Pakistan (DRAP) on June 12, 20208. There is no proper treatment for COVID-19 but symptomatic treatment has played an important role in the betterment of the diseased person's health. A number of drugs like remdesivir, chloroquine, hydroxychloroquine, corticosteroids and product of immunoglobulins are recommended by the health professionals ${ }^{9}$. It has been recommended by the Government of Pakistan to follow SOPs and avoid unnecessary gatherings in order to limit further spread of disease to others.

\section{EPIDEMIOLOGY}

The transmission of infectious agent is primarily linked to seafood wholesale market. The researchers detected RaTG13 gene from bats and supposed that pangolin and pigs are the possible intermediate host of Covid-19 Researchers supposed that bat is an initial host. Following studies suggested pig or pangolin as a possible intermediate host. It is due to the similarity between the SARS-CoV-2 and Bat-CoV RaTG13 gene. When the sea food market were closed the transmission of Covid-19 continued and rate of infected people increased day by day and later found out that zoonotic transmission of virus was the cause of spread $^{10}$. The human-to-human transmission SARSCoV-2 was also reported. This contagious infection is now widely distributed throughout the world affecting more than 210 countries and territories. Initially, China and Iran were the most affected ones in a very short period of time. Pakistan is the neighbor of both countries and has border and trade with both China and Iran, therefore, appearance of initial cases in the country had the history of travelling from Iran. It was also noted that mostly those people who had a recent history of travelling from foreign countries were detected positive for COVID-19. Since the beginning, Government of Pakistan had established quarantine centers in different areas of the country to limit the spread of the disease but due to lack of diagnostic facilities and resources, cases soared all over the country. All the provinces and territories of the country were put under lockdown for more than two months but the asymptomatic spread of disease was on peak due to which disease's spread occurred all over the country. 
Table 1. The Number of Cases and Deaths from COVID-19 in Different Provinces and Regions of Pakistan 5.

\begin{tabular}{ccccc}
\hline S. No. & Province / Regions & No. of Cases & No. of Deaths & References \\
\hline 1 & Sindh & 136,395 & 2,495 & 5 \\
\hline 2 & Punjab & 99,292 & 2,234 & 5 \\
\hline 3 & KPK & 37,727 & 1,259 & 5 \\
\hline 4 & Islamabad & 16,532 & 181 & 5 \\
\hline 5 & Balochistan & 15,177 & 145 & 5 \\
\hline 6 & GB & 3,730 & 88 & 5 \\
\hline 7 & AJK & 2,636 & 72 & 5 \\
\hline
\end{tabular}

Table 2. Different Diagnostic Facilities and Their Location in Pakistan Provinces and Regions.

\begin{tabular}{|c|c|c|c|c|}
\hline S. No. & Province/ Location & No. of Centres & & Address / Facilities \\
\hline \multirow{5}{*}{1} & \multirow{5}{*}{ Sindh } & \multirow{5}{*}{05} & 1) & Agha Khan University Hospital, Karachi \\
\hline & & & 2) & Dow Hospital, Ojha Campus, Karachi \\
\hline & & & 3) & Civil Hospital, Karachi \\
\hline & & & 4) & Indus Hospital, Karachi \\
\hline & & & 5) & South City Hospital, Karachi \\
\hline \multirow{4}{*}{2} & \multirow{4}{*}{ Punjab } & \multirow{4}{*}{04} & 1) & $\begin{array}{l}\text { Public Health Lab, Punjab AIDS Control Program, } \\
\text { Lahore }\end{array}$ \\
\hline & & & 2) & Shaukat Khanum Hospital, Lahore \\
\hline & & & 3) & Nishtar Hospital, Multan \\
\hline & & & 4) & $\begin{array}{l}\text { Armed Forces Institute of Pathology (AFIP), } \\
\text { Rawalpindi }\end{array}$ \\
\hline 3 & Islamabad & 01 & 1) & National Institute of Health (NIH), Islamabad \\
\hline 4 & KPK & 01 & 1) & $\begin{array}{l}\text { Public Health Lab, Khyber Medical University, } \\
\text { Peshawar }\end{array}$ \\
\hline 5 & Baluchistan & 01 & 1) & $\begin{array}{l}\text { Public Health Lab, Fatima Jinnah General and } \\
\text { Chest/TB Hospital, Quetta }\end{array}$ \\
\hline 6 & AJK & 01 & 1) & $\begin{array}{l}\text { Abbas Institute of Medical Sciences (AIMS), } \\
\text { Muzaffarabad }\end{array}$ \\
\hline 7 & GB & 01 & 1) & District Headquarters Hospital, Gilgit \\
\hline 8 & NIH Mobile Testing Lab & 01 & 1) & $\begin{array}{l}\text { Deployed at Taftan, Iran International Border } \\
\text { Crossing }\end{array}$ \\
\hline
\end{tabular}

As of September 29, 2020, there were more than 311,516 cases and 6,474 deaths in Pakistan. Highest number of cases were from Sindh followed by Punjab, Khyber Pakhtunkhwa (KPK), Islamabad, Balochistan Gilgit Baltistan (GB) and Azad Jammu and Kashmir (AJK). Sindh province was on top with more than 136,395 confirmed cases and 2,495 deaths. The number of cases in other provinces and regions of Pakistan was as
Punjab 99,292, KPK 37,727, Islamabad 16,532, Balochistan 15,177, GB 3,730 and AJK 2,636. Numbers of deaths were: Sindh 2,495, Punjab 2,234, KPK 1,259, Islamabad 181, Balochistan 145, GB 88 and AJK 72 (Table 1) $)^{5}$.

People of every age had acquired COVID-19, but most severe outcomes of the disease were observed in asthmatic patients, people of older age, cancer patients 
and other immunodeficient persons. It was also seen that males were more susceptible to infection as compared to females. Health care workers including doctors, nurses and others also suffered from disease and many of them have lost their lives.

\section{Strategies for Diagnosis, Treatment and Prevention in Pakistan}

Pakistan, is a developing country usually facing a financial crisis due to which outbreak like the current COVID-19 has more negative impacts on the economy of country. Due to lack of resources and health facilities, it is difficult to screen the whole population for disease, however, few diagnostic centers have been established by the government in different regions of the country, and are working to approach for further COVID-19 Health Advisory Platform by Ministry of National Health Services Regulation Coordination (Table 2).

Scientists have also started working on designing different reliable diagnostic kits and producing its own ventilators which are approved by DRAP and will be soon handed over to the National Disaster Management Agency $(\mathrm{NDMA})^{8}$. Strategies for viral diagnosis in Pakistan include swab (mouth or nose) sampling, serological testing of blood samples, molecular detection of viral particles by RT-PCR, lungs scans and detection of immunoglobulin. More severe cases are admitted to different quarantine centers and teaching hospitals where they are placed in isolation wards and properly cared and treated. Use of some drugs like remdesivir, chloroquine, hydroxychloroquine, corticosteroids and passive immunization has been observed for the treatment of severe COVID-19 patients ${ }^{11}$.

Due to economic crisis of the country and limited resources of health, it is difficult to manage such a high number of cases, therefore, the government has advised people to stay isolated at home if someone has a mild infection. For the management of severe cases, authorities in Pakistan has taken precautionary measures in the form of quarantine centers and isolation wards ${ }^{12}$. As there is no proper treatment for current COVID-19 hence, it is recommended by the Government of Pakistan to follow WHO guidelines and SOPs for COVID-19. On a community level, every individual should wear a surgical mask, keep social distance (6 feet), use sanitizers, frequently wash hands with soap, and avoid crowded gatherings and unnecessary travelling until the pandemic is controlled ${ }^{13}$.

\section{CONCLUSION}

Pakistan is a developing country in the neighborhood of China and Iran which were initially affected by COVID-19. Unfortunately, the country is facing an economic crisis due to which it becomes difficult to manage and face the fast-growing pandemic effectively. However, the initial steps that were taken by the government such as screening the passengers at airports and borders, partial or complete lockdown, following SOPs and establishment of quarantine centers for isolation of confirmed and suspected persons remained helpful for the country. Due to lack of health facilities, number of cases and deaths were seen all over the country and resulted in more than 311,516 cases and 6,474 deaths up to September 29, 2020. With such limited resources, the country is struggling for the invention of their diagnostic kits, ventilators and therapeutic drugs and vaccines. Since there is no proper treatment for COVID-19 yet therefore, it is recommended by the Government of Pakistan to properly follow SOPs and prevent others from deadly virus infection spread.

\section{CONFLICTS OF INTEREST}

None.

\section{FUNDING SOURCE}

None.

\section{ACKNOWLEDGEMENTS}

I am thankful all my colleges for data collection and analysis throughout this work.

\section{LIST OF ABBREVIATIONS}

COVID-19 Coronavirus disease-2019

DRAP Drug Regulatory Authority of Pakistan

NCP Novel coronavirus pneumonia

NDMA National Disaster Management Agency

NAAT Nucleic Acid Amplification Test 


\section{REFERENCES}

1. S. Bilgin O Kurtkulagi, G.B. Kahveci, T.T. Duman, B. M.A Tel. Millennium pendemic: a review of coronavirus disease (COVID-19) Exp Bioned Res. 3 (2) (220), pp. 117-125.

2. Huang C, Wang Y, Li X, Ren L, Zhao J, Hu Y, et al. Clinical features of patients infected with 2019 novel coronavirus in Wuhan, China. Lancet. 2020; 395(10223): 497-506.

3. Hui DS, Zumla A. Severe acute respiratory syndrome: historical, epidemiologic, and clinical features. Inf Dis Clin. 2019; 33(4):869-89.

4. Waris A, Khan AU, Ali M, Ali A, Baset A. COVID-19 outbreak: Current scenario of Pakistan. New Mic New Inf. 2020; 35: 681-7.

5. Saqlain M, Munir MM, Ahmed A, Tahir AH, Kamran S. Is Pakistan prepared to tackle the coronavirus epidemic? Drug Ther Pers. 2020; 36:213-4.

6. COVID-19 Health advisory platform by Ministry of National Health Services Regulation Coordination. http://covid.gov.pk/stats/pakistan.

7. Velavan TP, Meyer, CG. The COVID-19 epidemic. Trop Med Int Health. 2020; 25(3):278-84.
8. Drug regulatory authority of Pakistan (DRAP). https://www.dra.gov.pk/.

9. Lu R, Zhao X, Li J, Niu P, Yang B, Wu H et al. Genomic characterisation and epidemiology of 2019 novel coronavirus: Implications for virus origins and receptor binding. Lancet 2020; 395(10224):565-74.

10. Sun P, Qie S, Liu Z, Ren J, Xi J. Clinical Characteristics of 5732 patients with 2019-nCoV infection. 2020. Available at: SSRN 3539664.

11. Ilyas N, Azuine RE, Tamiz A. COVID-19 pandemic in Pakistan. Int J Trans Med Pub Heal. 2020; 4(1): 3749.

12. Mansoor SN, Gill ZA, Rathore FA, Uttra KM. Establishing and managing a quarantine and isolation centre in COVID-19 pandemic. J Pak Med Ass 2020; 70(5):11-4.

13. Uyeki TM, Bundesmann M, Alhazzani W. Clinical management of critically ill adults with coronavirus disease 2019

(COVID-19).

https://www.cdc.gov/coronavirus/2019-

ncov/index.html. 